\title{
Exposure to Cadmium Impairs Sperm Functions by Reducing CatSper in Mice
}

\author{
Hua-Feng Wang ${ }^{b, c}$ Meng Chang ${ }^{a, c}$ Ting-Ting Peng ${ }^{a, c}$ Yi Yang ${ }^{d}$ Na Li ${ }^{b}$ Tao Luo ${ }^{b, c}$ \\ Yi-Min Cheng ${ }^{b, c}$ Meng-Zhi Zhou ${ }^{a, b, c} \quad$ Xu-Hui Zeng ${ }^{b, c} \quad$ Li-Ping Zheng ${ }^{a, b, c}$ \\ aMedical Teaching Laboratory Center, Jiangxi Medical College, Nanchang University; ${ }^{\text {bInstitute }}$ \\ of Life Science and School of Life Science, Nanchang University; cJiangxi Key Laboratory of \\ Reproductive Physiology and Pathology; ${ }^{d}$ School of the 1st Clinical Medical Sciences, Jiangxi Medical \\ College, Nanchang University, Nanchang, Jiangxi, PR China
}

\section{Key Words}

Cadmium • Sperm function $\cdot$ CatSper $・$ Patch-clamp • Male reproduction

\begin{abstract}
Background: Cadmium (Cd), a common environmental heavy metal and endocrine disruptor, is known to exert toxic effects on the testes. However, the mechanisms accounting for its toxicity in mature spermatozoa remain unclear. Methods: Adult male C57BL/6 mice were orally administered with $\mathrm{CdCl}_{2}$ for 5 weeks at $3 \mathrm{mg} \cdot \mathrm{kg}^{-1} \cdot \mathrm{day}^{-1}$. Additionally, mouse spermatozoa were incubated in vitro with different doses of $\mathrm{CdCl}_{2}(0,10,50,250 \mu \mathrm{M})$. Several sperm functions including the sperm motility, viability and acrosome reaction (AR) ratio were then examined. Furthermore, the current and expression levels of both the sperm-specific $\mathrm{Ca}^{2+}$ channel (CatSper) and the sperm-specific $\mathrm{K}^{+}$channel (KSper) were evaluated by patch-clamping and western blotting, respectively. Results: Our data showed that the motility, viability and AR of sperm exposed to cadmium significantly decreased in vivo and in vitro. Interestingly, these changes were correlated with changes in CatSper but not KSper. Conclusion: The findings indicate sperm dysfunction during both chronic and acute cadmium exposure as well as a specific role for CatSper in the reproductive toxicity of cadmium.
\end{abstract}

\section{Introduction}

Recently, the reproductive toxicity caused by heavy metal contamination has been a matter of increasing concern. Cadmium, which is one of the most common environmental and occupational metallic toxicants, has also been demonstrated to potentially threaten human health [1-3]. Due to its high toxicity and cumulative effect, Cd easily leads to multiorgan injury, especially to the genital system [4-6]. Compared with other organs, the testes, which are the male gonads, are more vulnerable to toxicants because of their active cell division and metabolism [7-11]. A recent report used the measurement of semen quality as a marker of environmental pollution due to cadmium [12]. However, previous studies on H.-F. Wang and M. Chang contributed equally to this work. 


\section{Cellular Physiology Cell Physiol Biochem 2017;42:44-54 \begin{tabular}{l|l} 
and Biochemistry Published online:May 11, 2017 & $\begin{array}{l}\text { D } 2017 \text { The Author(s). Published by S. Karger AG, Basel } \\
\text { www.karger.com/cpb }\end{array}$ \\
\hline
\end{tabular}}

Wang et al.: Cadmium Impairs Mouse Sperm Functions

cadmium-induced toxicity in the male reproductive system focused more on the interference with spermatogenesis [13], damage to nuclear DNA [14], and causes of apoptosis [15], while the toxicity and mechanisms of cadmium in mature spermatozoa are still unclear.

Produced initially in the testes, sperm are quiescent in the male reproductive tract and then mature in the epididymis. During ejaculation, sperm must undergo a series of challenges to acquire fertilization competence prior to fusing with the oocyte [16-18]. Because of transcriptional gene silencing in sperm, these physiological processes for fertilization are generally triggered by the activation of ion channels on the sperm membrane [17-20]. With the establishment of the sperm patch clamp [21], the functional and molecular characteristics of ion channels in mature sperm could then be directly studied by electrophysiological methods. Among these channels, the sperm-specific $\mathrm{Ca}^{2+}$ channel (CatSper) and $\mathrm{K}^{+}$channel (KSper) are essential for male fertility in mammals [21-24].

It has been previously proposed that the sperm-specific cation channel (CatSper) acts as the main intracellular $\mathrm{Ca}^{2+}$ source and may cause several $\mathrm{Ca}^{2+}$-dependent responses (motility, chemotaxis, and the acrosome reaction) [22, 25-29], whereas the sperm-specific potassium channel (Slo3) accounts for hyperpolarization of the membrane potential [24, 30]. Further studies have also revealed that both CatSper and KSper are indispensable to male fertility and that any mutation of either channel will cause male infertility [30, 31].

Many studies in multiple cell systems showed that one of the toxicity mechanisms by which heavy metals disrupt cellular function depends on their similarities in charge or size to ions, thus competing with the related ions or hindering their normal membrane permeation. In this study, we aimed to evaluate changes in sperm function after exposure to cadmium and explore related mechanisms in vivo by orally administering cadmium chloride $\left(\mathrm{CdCl}_{2}\right)$ according to ref [31] and in vitro by applying 10,50, and $250 \mu \mathrm{M} \mathrm{CdCl}_{2}$ to sperm. Several sperm functions such as viability, motility, and acrosome reaction (AR) were examined. Furthermore, both CatSper and KSper currents were tested by patch-clamping, and their gene or protein expression levels were observed simultaneously. Taken together, the results might help to illuminate a novel mechanism underlying the effects of heavy metals on the regulation of reproductive function.

\section{Materials and Methods}

\section{Experimental animals}

Male C57BL/6 mice (25-35 g; 7-9 weeks) were purchased from the Animal Center of Nanchang University. The mice were housed at a temperature of $20 \sim 25^{\circ} \mathrm{C}$ under a $12 / 12 \mathrm{~h}$ light/dark schedule and then sacrificed after receiving oral $\mathrm{CdCl}_{2}$ (Sigma, USA) at $3 \mathrm{mg} \cdot \mathrm{kg}^{-1} \cdot \mathrm{day}^{-1}$ for 5 weeks. All animals were treated humanely, and this study was approved by the Animal Care and Use Committee of Nanchang University.

After sacrifice on day 36, the testes were separated, and the spermatozoa were released from the epididymis into HS solution (135 mM NaCl, $5 \mathrm{mM} \mathrm{KCl,} 1 \mathrm{mM} \mathrm{MgSO}_{4}, 2 \mathrm{mM} \mathrm{CaCl}_{2}, 20 \mathrm{mM} \mathrm{HEPES}, 5 \mathrm{mM}$ glucose, $10 \mathrm{mM}$ lactic acid, and $1 \mathrm{mM}$ Na-pyruvate at $\mathrm{pH} 7.4$ with $\mathrm{NaOH}$ ) or human tubal fluid (HTF) (Millipore, USA) capacitation medium. The sperm concentration was calculated and recorded for the subsequent experiments.

\section{Serum cadmium analysis}

Blood collected from the angular artery was centrifuged at $2500 \mathrm{rpm}$ for $10 \mathrm{~min}$, and the serum was collected and frozen at $-80^{\circ} \mathrm{C}$ for later analysis. The $\mathrm{Cd}$ concentrations in the mouse blood were analyzed by atomic absorption spectrophotometry (AAS) and were calculated using the following formula: $\mathrm{Cd}(\mu \mathrm{g} / \mathrm{g})$ $=\mathrm{Cx} \times \mathrm{nW}(\mathrm{W}$ : weight of sample, $\mathrm{n}$ : dilution, $\mathrm{Cx}$ : value from standard curve).

Testes histological examination

The testes were fixed in $4 \%$ paraformaldehyde for at least $24 \mathrm{~h}$ and then dehydrated in graded ethanol to make paraffin blocks. A 5- $\mu$ m tissue section cut with a Leica microtome was stained using a routine hematoxylin/eosin staining technique and then examined using a Leica DM2500 Upright Microscope. 


\section{Cellular Physiology Cell Physiol Biochem 2017;42:44-54 and Biochemistry Published online: May 11, $2017 \quad \begin{aligned} & \text { DOI: 10.1159/000477113 } \\ & \begin{array}{l}\text { c) } 2017 \text { The Author(s). Published by S. Karger AG, Basel } \\ \text { ww.karger.com/cpb }\end{array}\end{aligned}$}

Wang et al.: Cadmium Impairs Mouse Sperm Functions

Computer-assisted sperm analysis (CASA)

The total sperm motility (\%) before and after $\mathrm{CdCl}_{2}$ addition was analyzed using a CASA system (WLJY9000, China), as previously described [31]. For the in vitro study, sperm were incubated with different $\mathrm{CdCl}_{2}$ concentrations $(0,10,50,250 \mu \mathrm{M})$ for $60 \mathrm{~min}$ at $37^{\circ} \mathrm{C}$ in $5 \% \mathrm{CO}_{2}$. Afterwards, a $10-\mu \mathrm{L}$ sperm suspension was placed in a preheated $\left(37^{\circ} \mathrm{C}\right)$ observation chamber, and the motility was then evaluated, including the PR (progressive ratio) and NP (non-progressive ratio). Sperm viability was assessed via eosin-nigrosin staining. The dead sperm would appear pink, while the live sperm would not be stained. A minimum of 200 spermatozoa were counted for each assay.

Acrosome reaction (AR) assessment

The acrosome reaction was assessed by chlortetracycline (CTC) (Sigma, USA) staining as previously reported [31, 32]. Epididymal sperm were released and capacitated in HTF medium for $60 \mathrm{~min}$ in the presence or absence of $\mathrm{CdCl}_{2}$ and progesterone $(10 \mu \mathrm{M})$. After lowspeed centrifugation for $10 \mathrm{~min}$, the resulting sperm precipitate was resuspended in 100 $\mathrm{L}$ of HTF and equivalent CTC solution for $20 \mathrm{~min}$ at $37^{\circ} \mathrm{C}$ in $5 \% \mathrm{CO}_{2}$. The stained sperm were then collected, fixed and examined by using a Leica DM2500 Upright Microscope under epifluorescent illumination with ultraviolet BP340-380 (Leica "A" filter, Germany). Three different sperm patterns were observed: the F pattern (yellow fluorescence distributed uniformly over the head), which meant non-capacitated sperm; the B pattern (yellow fluorescence over the acrosomal region but a dark post-acrosomal region), which meant non-capacitated sperm; and the AR pattern (a very weak or no fluorescence over the head), which was taken to be indicative of acrosome-reacted sperm. At least 200 spermatozoa were counted to assess the CTC staining status.

\section{Sperm patch-clamp recordings}

Whole-cell currents were recorded by patch-clamping the sperm cytoplasmic droplet as reported previously [24]. Epididymal sperm were obtained and suspended in dissociation solution (HS). For recording of the CatSper current, a sodium-based divalent-free (DVF) solution containing $150 \mathrm{mM} \mathrm{NaCl}$, $20 \mathrm{mM}$ HEPES, and $5 \mathrm{mM}$ EDTA at pH 7.4 was used, while the pipette solution contained $135 \mathrm{mM}$ Cs-MES, $10 \mathrm{mM}$ HEPES, $10 \mathrm{mM}$ EGTA, and $5 \mathrm{mM} \mathrm{CsCl}$ adjusted to a pH 7.2 with $\mathrm{CsOH}$. For KSper, an extracellular solution containing $160 \mathrm{mM} \mathrm{KOH,} 10 \mathrm{mM}$ HEPES and $150 \mathrm{mM}$ MES (pH was adjusted to 7.4 with MES). The symmetrical $160 \mathrm{mM} \mathrm{K}^{+}$pipette solution contained $155 \mathrm{mM} \mathrm{KOH,} 5 \mathrm{mM} \mathrm{KCl}, 10 \mathrm{mM}$ 1,2-bis(2-aminophenoxy) ethane- $\mathrm{N}, \mathrm{N}, \mathrm{N}^{\prime}, \mathrm{N}^{\prime}$-tetraacetic acid (BAPTA), $20 \mathrm{mM}$ HEPES, and $115 \mathrm{mM}$ MES (pH was adjusted to 8.0 with $\mathrm{KOH}$ ). The different doses of $\mathrm{CdCl}_{2}$ were prepared in the extracellular solution. All currents were analyzed with Clampfit (Axon, Gilze, Netherlands) and Grapher 8 software (Golden Software, Inc., Golden, CO, USA).

\section{Real-time PCR analysis}

To assess mRNA expression of target genes in mice with or without cadmium exposure, real-time quantitative reverse transcriptase PCR (qRT-PCR) was conducted according to a previously described method [31]. The total RNA was extracted from mouse testes using Trizol reagent (Ambion, USA) and was treated with the DNA-free Kit (Takara; USA) to remove genomic DNA. cDNA was synthesized from the total RNA with a RT-PCR kit (Takara, USA) according to the manufacturer's instructions. The mRNA expression was assessed in a StepOnePlus RT-PCR system (Applied Biosystems, USA) with specific primers. The primer sequences for CatSper1-4, Slo3 and $\beta$-actin were designed according to previous publications [31]. The $2^{-\Delta \Delta C t}$ method was utilized to evaluate the relative expression normalized to $\beta$-actin expression. The results were averaged from four sets of independent experiments.

\section{Western blot}

To detect the protein expression of CatSper and Slo3 in chronic cadmium-treated mice, the extracted testes proteins were mixed with SDS Loading Buffer. Protein samples were electrophoresed on 10\% SDSpolyacrylamide gels and were transferred onto polyvinylidene difluoride membranes (GE Healthcare, USA). Five percent skim milk powder was used to block nonspecific binding sites for $1 \mathrm{~h}$. After being washed with TBST, the membrane was incubated with corresponding primary antibodies (Abcam, USA) at $4^{\circ} \mathrm{C}$ overnight. After incubation with HRP-conjugated goat anti-rabbit/mouse IgG (Thermo Scientific, USA) for $1 \mathrm{~h}$, the protein level was visualized using an ECL detection kit (Thermo Scientific, USA). 
Statistical analysis

The results are presented as the mean \pm SEM. One-way analysis of variance (ANOVA) followed by Student's t-test was used to determine significant differences indicative of changes between the control and the treated groups with GraphPad Prism 6. The results were considered statistically significant when $p<0.05$.

\section{Results}

Chronic cadmium exposure could harm the motility, viability and AR of mouse sperm

To observe the reproductive toxicity of $C d$ in mature sperm, a chronic cadmium poisoning model was built by orally dosing the mice with $\mathrm{CdCl}_{2}$ at $3 \mathrm{mg} \cdot \mathrm{kg}^{-1} \cdot \mathrm{day}^{-1}$ for 5 weeks. Whether the model was built successfully was initially identified through the measurement of Cd concentration in blood as well as the change in the index of testis (the ratio of testis weight to body weight) (as is shown in Table 1 and 2) and the testicular histology (Fig. 2). After epididymal sperm collection, three essential parameters, including motility, progressive motility and viability, were examined by CASA and were found to be significantly decreased $(\mathrm{P}<0.05)$ in Cd-treated mice (Fig. 1A, B and C).

In mammals, the acrosome reaction is crucial for sperm to fuse with the oocyte [25]. Here, both spontaneous and progesterone-induced ARs were examined in cadmium-treated mice. Compared with the control group, the spontaneous AR declined significantly (Fig. 1D). Although the progesterone-induced AR also decreased in cadmium-treated mice, the percentage of decrease is similar to that of the spontaneous AR ( $8.9 \%$ vs $9.8 \%)$. It seemed that only the spontaneous AR was affected by cadmium in vivo. Collectively, these results show that testicular tissue, sperm motility, and spontaneous AR were all impaired after cadmium exposure, which indicated enormous damage by cadmium to the functions of mature sperm.

Table 1. Cadmium accumulation in mice blood after cadmium exposure

\begin{tabular}{lc}
\hline Group & Concentration $(\mu \mathrm{g} / \mathrm{L})$ \\
\hline Control group $(\mathrm{n}=5)$ & $0.53 \pm 0.16$ \\
Treatment group $(\mathrm{n}=5)$ & $37.24 \pm 0.48^{\text {*** }}$ \\
\hline
\end{tabular}

Table 2. Effects of cadmium exposure on mouse testis index

\begin{tabular}{lc}
\hline Group & Testis index $(\mathrm{mg} / \mathrm{g})$ \\
\hline Control group $(\mathrm{n}=5)$ & $6.45 \pm 0.17$ \\
Treatment group $(\mathrm{n}=5)$ & $1.56 \pm 0.44^{* *}$ \\
\hline
\end{tabular}

Fig. 1. 5 weeks of cadmium administration impaired sperm motility and acrosome reaction significantly. Cadmium administration inhibited sperm total motility (A), progressive motility (B) and viability (C). Both the spontaneous AR and progesterone (P4) induced AR (D) were impaired after cadmium administration. Bars indicate the mean \pm SEM; $n=5$ for each panel. ${ }^{*} p<0.05,{ }^{* *} p<$ 0.01 , and ${ }^{* * *} p<0.001$.

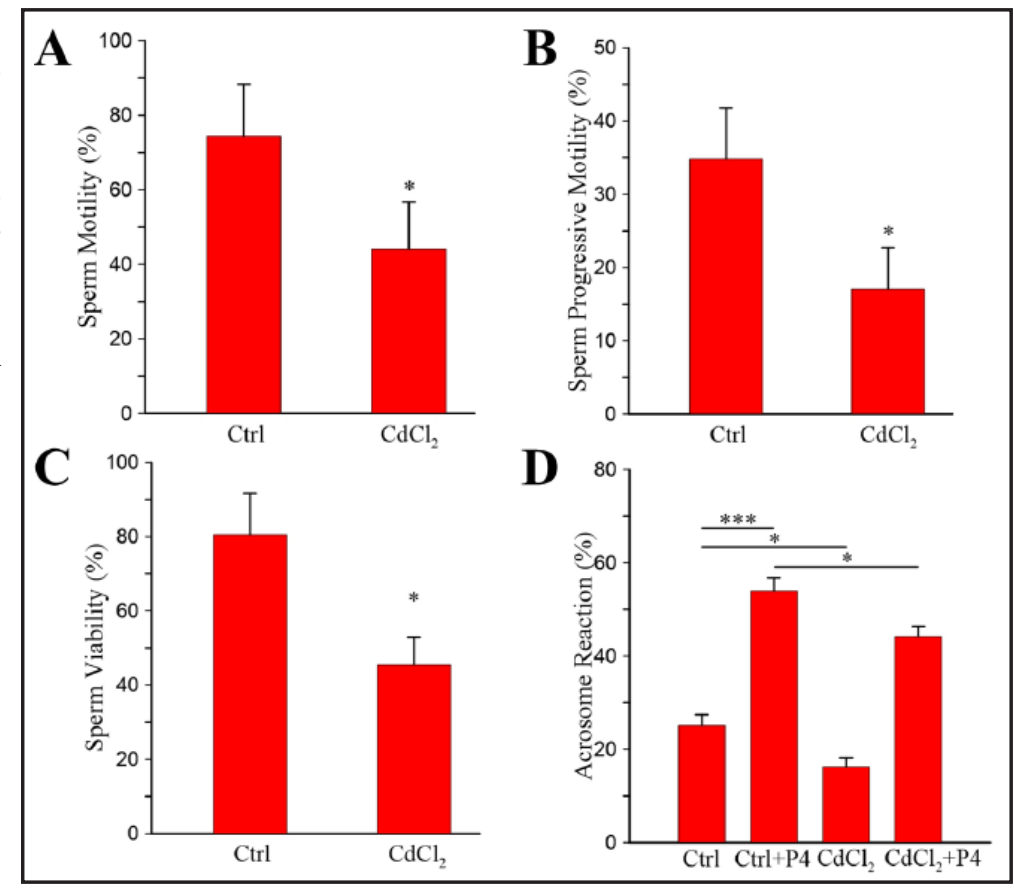




\section{Cellular Physiology and Biochemistry

Fig. 2. HE staining results of testis with or without cadmium exposure. A. Control mouse testis; B. Cadmium-treated mouse testis. (100X).

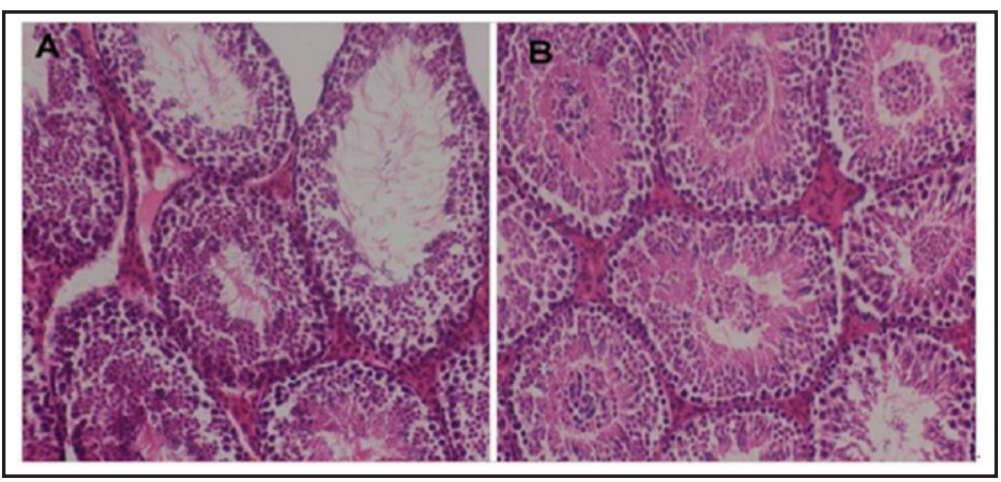

Fig. 3. CatSper (sperm-specific $\mathrm{Ca}^{2+}$ current) but not KSper (sperm-specific $\mathrm{K}^{+}$current) were reduced in sperm from cadmium-treated mice. (A) CatSper currents recorded by a ramp protocol from mice treated with $\mathrm{CdCl}_{2}$. (B) Averaged CatSper amplitudes measured at both $-100 \mathrm{mV}$ and +100 $\mathrm{mV}$ from each sperm group. (C) Ramp KSper currents recorded from each group. (D) Averaged KSper amplitudes for each group. Bars indicate the mean \pm SEM; the numbers of cells tested are shown in the figure. ${ }^{*} p<0.05,{ }^{* *} p<0.01$, and ${ }^{* * *} p<0.001$.

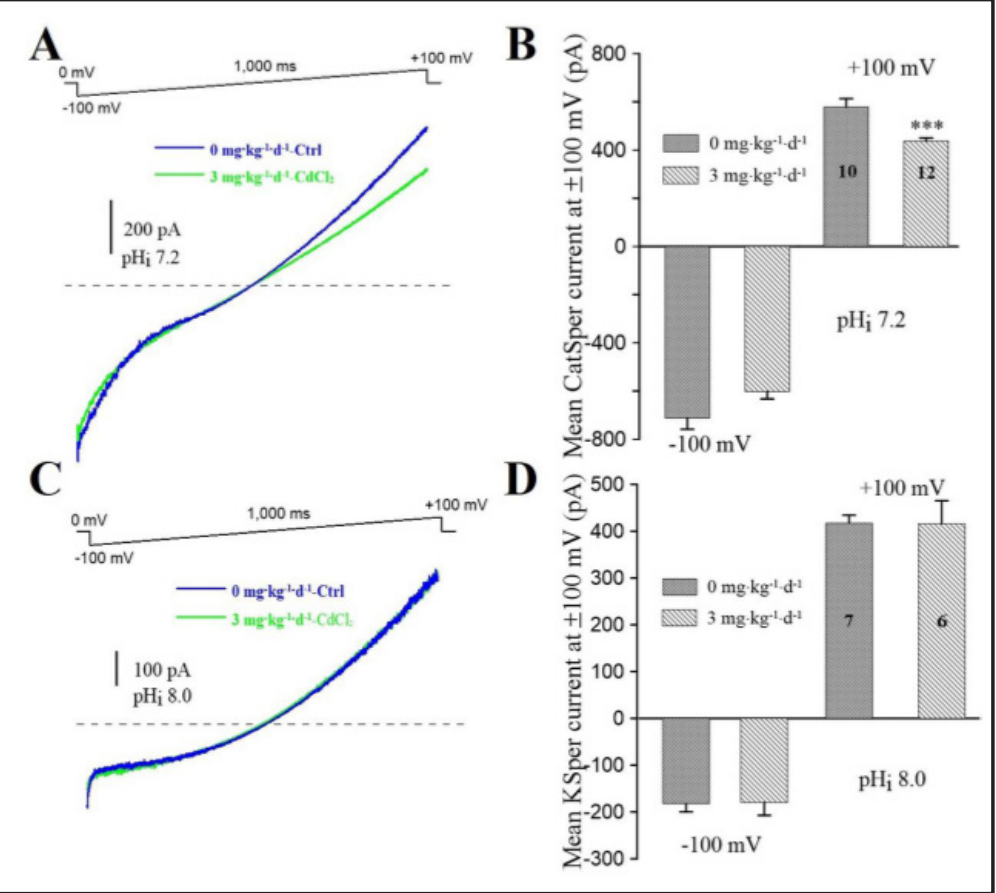

CatSper current was reduced in cadmium-treated mice, while KSper was uninfluenced

The CatSper channel, which is specifically located on the mammalian sperm flagellum, mediates a series of sperm functions [22, 26, 27, 33]. In view of the channel's vital role, we tried to further observe whether cadmium treatment caused functional impairment via the CatSper abnormality. As shown in Fig. 3A and B, the CatSper current was elicited by a ramp protocol from $-100 \mathrm{mV}$ to $+100 \mathrm{mV}$ and declined by $24.4 \%$ at $+100 \mathrm{mV}$ in cadmium-treated mice compared with the control group $(\mathrm{P}<0.001)$. Furthermore, another pH-sensitive channel of sperm, KSper, mediates the membrane potential of sperm and is also thought to be involved in sperm motility and the AR. To investigate whether cadmium affected KSper specifically, we next recorded the KSper current, which was elicited by using the same protocol. No significant difference was observed between the cadmium-treated mice and the control group (Fig. 3C and D). Accordingly, the impaired sperm functions caused by cadmium exposure may result from the lower CatSper current.

The expression levels of CatSper subunits were also reduced variously

The CatSper current decreased in the cadmium-treated mice, as shown above, which suggested that the expression level of CatSper subunits might be influenced by cadmium. Previous studies proposed that the CatSper channel was composed of four different poreforming subunits (CatSper1-4) [22, 34], and any mutation of these subunits would abolish the CatSper current [33]. Therefore, it is necessary to clarify whether the decrease of 


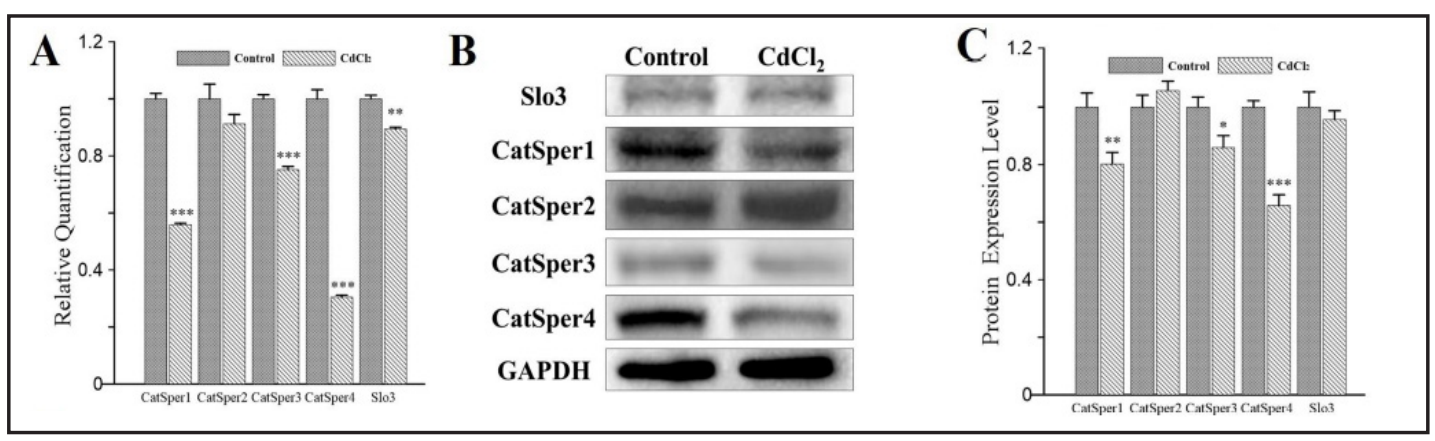

Fig. 4. The mRNA and protein expression levels of CatSper subunits decreased in cadmium-treated mice. (A) The mRNA levels of CatSper1-4 and Slo3 subunits in cadmium treated mice. (B) The protein levels of CatSper1-4 in cadmium-treated mice. (C) Statistical results for protein levels. Bars indicate the mean \pm SEM; $n=3 ;{ }^{*} p<0.05,{ }^{* *} p<0.01$, and ${ }^{* * *} p<0.001$.

the CatSper current in the cadmium-treated mice results from gene expression changes of these pore-forming subunits. As shown in Fig. 4, both the mRNA and protein levels of the CatSper subunits exhibited diverse modification. CatSper1, CatSper3, and especially CatSper4 were downregulated dramatically after cadmium exposure. However, CatSper2 showed no obvious difference. In contrast, the mRNA level of Slo3, the pore-forming subunit of the KSper channel, decreased slightly (Fig. 4A), whereas the protein level did not show a significant decrease (Fig. 4B and C), which corresponded to the KSper current (Fig. 3C and D). This discrepancy may result from a post-translational modification conferring resistance to cadmium stress. Overall, these results imply that the decreased expression of CatSper resulted in the decrease of the CatSper current.

Cadmium inhibited mouse sperm viability, motility and AR in vitro

After ejaculation, spermatozoa can be maintained for days under the conditions of the female reproductive tract. Spermatozoa must overcome several barriers to fuse with the oocyte and are potentially faced with cadmium exposure. Therefore, it is necessary to determine whether cadmium may interfere with sperm functions in vitro. Spermatozoa were incubated with four different cadmium concentrations $(0,10,50$, and $250 \mu \mathrm{M})$ for 60 min and were then subjected to motility analysis. The results showed that sperm viability decreased only at $250 \mu \mathrm{M}$ (Fig. 5A), while sperm motility declined significantly at 50 and $250 \mu \mathrm{M}$ (Fig. 5B). After the sperm had been capacitated for $60 \mathrm{~min}$, both spontaneous and progesterone-induced ARs were assessed with cadmium exposure in vitro. Cadmium had no influence on the spontaneous AR (Fig. 5C), whereas it suppressed the progesterone-induced AR significantly at $250 \mu \mathrm{M}$ (Fig. 5D). From the above results, we speculate that cadmium could have an impact on the fertilization ability of spermatozoa with changes in viability, motility and the progesterone-induced AR.

Cadmium inhibited CatSper current but had no effect on KSper current in vitro

Our results above suggest that cadmium may impair sperm functions in vivo by affecting CatSper expression, resulting in a current decrease. To clarify whether cadmium inhibited sperm functions in vitro due to a targeted effect on the CatSper channel, we tested the effect of cadmium on the CatSper channel by whole-sperm patch. Sperm were perfused with a DVF solution containing different concentrations of cadmium chloride $(0,10,50$, and 250 $\mu \mathrm{M})$. The results demonstrated that direct cadmium application could inhibit the CatSper current transiently but dose-dependently (Fig. 6A and B). In contrast, cadmium had no effect on mouse KSper current even at $250 \mu \mathrm{M}$ (Fig6C and D). Overall, these results imply that the inhibitory effect of cadmium on mouse sperm functions may result from the reduction of the CatSper current in vitro. 
Fig. 5. Cadmium impaired the functions of mature sperm in vitro. The collected sperm were incubated in HS solution with various doses of cadmium $(0,10,50,250 \mu \mathrm{M})$ for $1 \mathrm{~h}$. Cadmium affected both sperm viability (A) and motility (B) with a dose-dependent manner. Meanwhile, cadmium suppressed the spontaneous AR (C) and P4 induced AR (D). Bars indicate the mean \pm SEM; $n=4{ }^{*} p<0.05,{ }^{* *} p<0.01$, and $* * * p<0.001$.

Fig. 6. Cadmium inhibited the sperm specific CatSper current while had no effect on KSper current. (A) CatSper current recorded at constantly $+100 \mathrm{mV}$ exhibited a transient inhibition by cadmium. (B) Normalized current measured at max inhibition showed a concentration-dependent manner. (C) Cadmium had no effect on KSper current in a certain extent. (D) Statistical results for (C). Bars indicate the mean \pm SEM. $n=4 ;{ }^{*} p<0.05,{ }^{* *} p<0.01$, and $* * * p<0.001$.
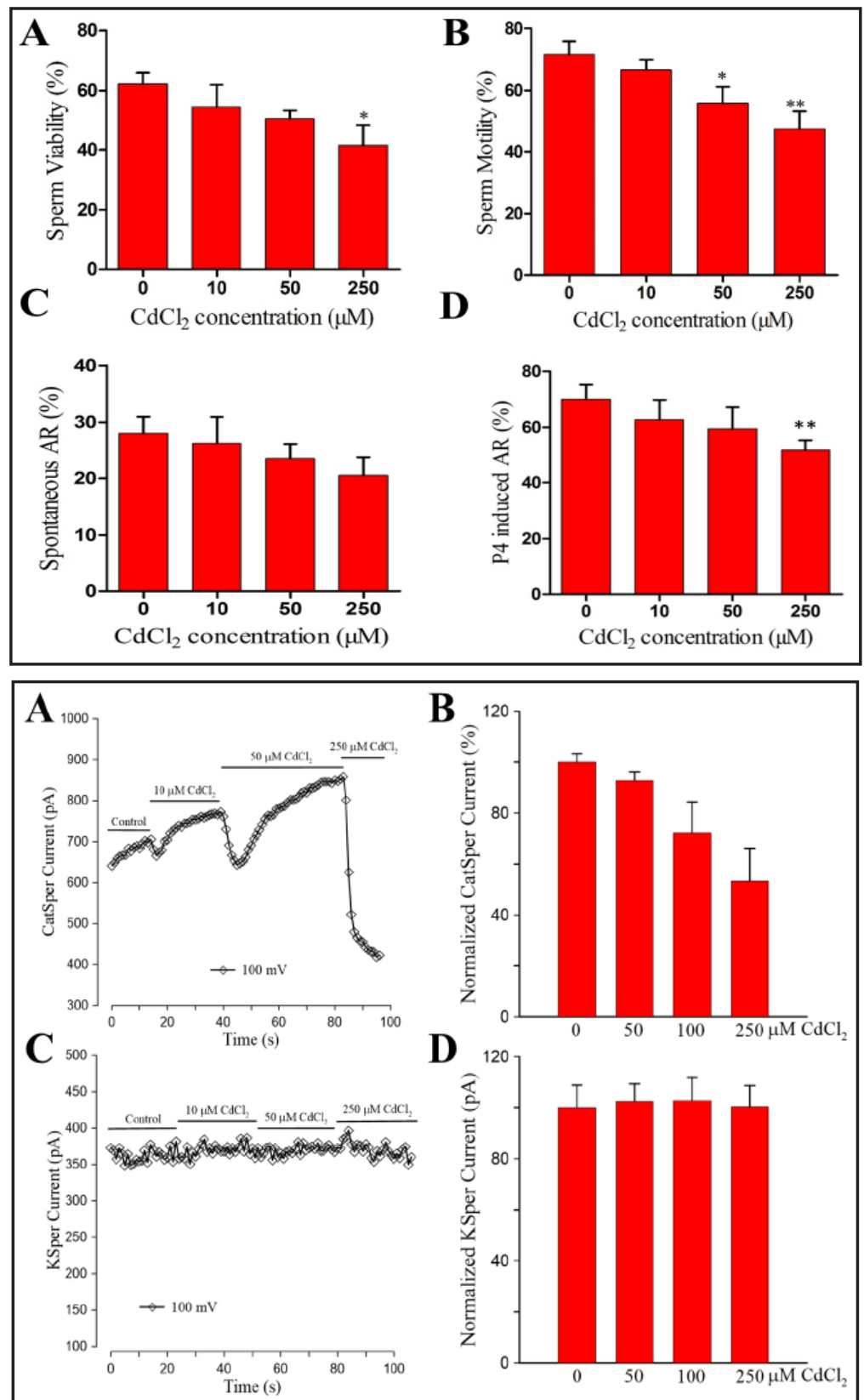

\section{Discussion}

Although the average daily intake of Cd is only approximately $0.35 \mathrm{mg} / \mathrm{kg}$ (ATSDR, 2012) for an adult male, the easy accumulation and long biological half-life (20-30 years in humans) of Cd [35] can injure individuals' liver, kidneys and reproductive system [36]. For the male reproductive system, $\mathrm{Cd}$ is enriched not only in the testes but also in the epididymis, where sperm become mature. Using a chronically Cd-poisoned mouse model [37] and an acute Cd exposure method, we tried to observe how chronic and acute cadmium exposure can affect the physiologic functions of mature sperm and explored the underlying mechanisms.

In this study, the method of administering cadmium to the mice and the dose of cadmium used were critical. Although there have been many methods to generate a chronically Cd-exposed animal model [37], it was still necessary to consider how to make the dose of cadmium, route of intake and pathological process of the experimental animal model similar to those of human beings in daily life. Additionally, it is important to note that 
the cadmium concentration in the testes of chronically Cd-poisoned animals was four times higher than that of high-dose injected animals, which is physiologically relevant to humans [38]. Therefore, we chose a dietary (drinking) cadmium intake method to create a chronic, oral, low-dose Cd-poisoned animal model [37]. According to normal individuals' permissible daily $\mathrm{Cd}^{2+}$ intake and the oral LD50 of $\mathrm{Cd}$ for mice, we chose an appropriate Cd dosage (3 $\mathrm{mg} \cdot \mathrm{kg}^{-1} \cdot$ day $^{-1}$ ). In addition, low concentrations of $\mathrm{CdCl}_{2}$ would be used for sperm incubation in vitro, including 10,50 , and $250 \mu \mathrm{M}$.

In our study, the results from both in vivo and in vitro experiments, which represent chronic $\mathrm{Cd}$ exposure in the male accessory gonads and short-term Cd exposure in the female reproductive tract, indicated that physiologic functions including the motility, progressive motility and AR of Cd-poisoned sperm decreased significantly, thus negatively affecting male fertility. The reason why sperm dysfunction was induced by $\mathrm{Cd}$ may lie in the intracellular calcium concentration, which is the key factor in regulating those essential processes of sperm.

Due to the special structure of sperm (scant cytoplasm and underdeveloped calcium storage), the influx of calcium becomes the dominant pathway for the increase of intracellular calcium $[39,40]$. Therefore, the sensitivity and permeability of calcium channels in the sperm membrane appears especially notable [41-43]. However, there has been little research in relation to the pathogenic mechanism of $\mathrm{Cd}$, limited by the difficulty of recording the sperm membrane current, which reflects the channel activity. Here, we agree with Zhou's opinion that cadmium was likely to affect sperm motility through the level of calcium entry, altered by calcium channel properties [44-47]. However, we believe CatSper, which is located in the principal piece of the sperm flagellum, was the foremost binding site of cadmium, causing toxicity.

CatSper, like other voltage-gated calcium channels, possesses a conserved calciumselective pore composed of four subunits (CatSper1-4) and three auxiliary subunits [48], and the channel seems to be exclusively evolved for sperm function and male fertility [22]. Owing to its sperm specificity, significant effect and high efficiency, CatSper has become a crucial target for research and treatment of male infertility as well as developing novel male contraceptives [40,49].

In our opinion, the mechanism for Cd-induced damage of sperm functions has the following aspects. First, Cd can directly affect the expression and activity of CatSper. Here, low gene transcription and protein expression of CatSper $(1,3,4)$ were observed, while the CatSper current recorded by the sperm whole-cell patch clamp markedly decreased, exhibiting an obviously dose-dependent toxic effect of $\mathrm{Cd}$ in vitro. Second, CatSper's permeability to $\mathrm{Ca}^{2+}$ would be disrupted by $\mathrm{Cd}$ exposure. A CatSper-like pore was recently generated and presented less sensitivity but stronger permeability to $\mathrm{Cd}^{2+}$ compared with other voltage-dependent calcium channels $[40,44,50]$. Furthermore, CatSper's permeability to $\mathrm{Cd}^{2+}$ in human spermatozoa was shown to be significantly increased by progesterone [5153], an essential physiological regulator in the microenvironment of the female reproductive tract, thus implying that excessive $\mathrm{Cd}^{2+}$ influx through CatSper could affect sperm function. Third, $\mathrm{Cd}^{2+}$, also known as one of the environmental endocrine-disrupting chemicals (EDCs), may affect the current of CatSper, since CatSper seems to be a polymodal, chemosensory calcium channel stimulated by a diverse range of chemicals such as the plasticizer bisphenol A (BPA) and 4-methylbenzylidene camphor (4-MBC) [31, 54, 55]. Finally, Cd poisoning probably damaged renal function $[56,57]$, leading to a decrease in blood $\mathrm{pH}$ and thereby inhibiting the activity of sperm CatSper.

Membrane potential hyperpolarization is a prerequisite for sperm capacitation, hyperactivation and other physiologic processes [58]. Furthermore, under physiological conditions, the main voltage-gated potassium channel that determined the membrane potential of sperm was Slo3 $[24,30]$. In this study, the effect of Cd on Slo3 was also evaluated, and it was found that $\mathrm{Cd}$ could inhibit the expression of Slo3 mRNA. However, unlike CatSper, the protein level of Slo3 and the amplitude of the KSper current did not significantly differ from those in the control group.

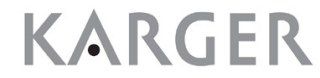




\section{Cellular Physiology Cell Physiol Biochem 2017;42:44-54 and Biochemistry Published online: May 11, $2017 \quad \begin{aligned} & \text { DOI 10159/2017 The Author(s). Published by S. Karger AG, Basel } \\ & \text { www.karger.com/cpb }\end{aligned}$}

Wang et al.: Cadmium Impairs Mouse Sperm Functions

Infertility has become a serious global public health problem. With the rapid development of modern industries, the reproductive impairment caused by environmental pollution should never be neglected. For the first time, we investigated the effect of heavy metal exposure on the activity of CatSper and KSper, which are crucial channels for the regulation of the physiologic function of mature sperm, to further illuminate the toxicological mechanism of heavy metal on male reproduction that might contribute to the decline in human fertility and to bring new ideas for therapeutic approaches. The specific signaling network remains to be further studied and explored.

\section{Acknowledgments}

The authors would like to thank Dr. Yuehui Zheng and Dr. Zhisheng Zhong for technical assistance; Zhengjia Wang in $2^{\text {nd }}$ middle school of Nanchang for syntax checking of the manuscript.

This work was supported by National Natural Science Foundation of China (81300539), Cultivation Plan for Young Scientists of Jiangxi Province (20153BCB23031) and Scientific Research Plan of Education Department in Jiangxi Province (GJJ13092).

\section{Disclosure Statement}

The authors declare no competing financial interests.

\section{References}

1 Cobbina SJ, Chen Y, Zhou Z, Wu X, Zhao T, Zhang Z, Feng W, Wang W, Li Q, Wu X, Yang L: Toxicity assessment due to sub-chronic exposure to individual and mixtures of four toxic heavy metals. Journal of Hazardous Materials 2015;294:109-120.

2 Nakadaira H, Nishi S: Effects of low-dose cadmium exposure on biological examinations. Science of The Total Environment 2003;308:49-62.

- Z Zhou Z, Lu YH, Pi HF, Gao P, Li M, Zhang L, Pei LP, Mei X, Liu L, Zhao Q Qin QZ, Chen Y, Jiang YM, Zhang ZH, Yu ZP: Cadmium Exposure is Associated with the Prevalence of Dyslipidemia. Cell Physiol Biochem 2016;40:633-643.

4 Akinloye 0, Arowojolu AO, Shittu OB, Anetor JI: Cadmium toxicity: a possible cause of male infertility in Nigeria. Reprod Biol 2006;6:17-30.

5 Yang H, Shu Y: Cadmium transporters in the kidney and cadmium-induced nephrotoxicity. Int J Mol Sci 2015;16:1484-1494.

6 Minutoli L, Micali A, Pisani A, Puzzolo D, Bitto A, Rinaldi M, Pizzino G, Irrera N, Galfo F, Arena S, Pallio G, Mecchio A, Germana A, Bruschetta D, Laura R, Magno C, Marini H, Squadrito F, Altavilla D: Research Article Flavocoxid Protects Against Cadmium-Induced Disruption of the Blood-Testis Barrier and Improves Testicular Damage and Germ Cell Impairment in Mice. Toxicol Sci 2015;148:311-329.

7 Alkhedaide A, Alshehri ZS, Sabry A, Abdel-Ghaffar T, Soliman MM, Attia H: Protective effect of grape seed extract against cadmium-induced testicular dysfunction. Mol Med Rep 2016;13:3101-3109.

8 Oliveira H, Spano M, Santos C, Pereira Mde L: Adverse effects of cadmium exposure on mouse sperm. Reprod Toxicol 2009;28:550-555.

-9 Yang HS, Han DK, Kim JR, Sim JC: Effects of alpha-tocopherol on cadmium-induced toxicity in rat testis and spermatogenesis. J Korean Med Sci 2006;21:445-451.

10 Niknafs B, Salehnia M, Kamkar M: Induction and determination of apoptotic and necrotic cell death by cadmium chloride in testis tissue of mouse. J Reprod Infertil 2015;16:24-29.

-11 Hussein AM, Mustafa HN, Badawoud MH: Ameliorative potentials of a combination of fenugreek and alpha-tocopherol on cadmium induced testicular toxicity: an ultrastructural study. Folia Morphol (Warsz) 2015;74:325-334.

12 De Franciscis P, Ianniello R, Labriola D, Ambrosio D, Vagnetti P, Mainini G, Trotta C, Mele D, Campitiello MR, Caprio F: Environmental pollution due to cadmium: measure of semen quality as a marker of exposure and correlation with reproductive potential. Clin Exp Obstet Gynecol 2015;42:767-770. 


\section{Cellular Physiology Cell Physiol Biochem 2017;42:44-54

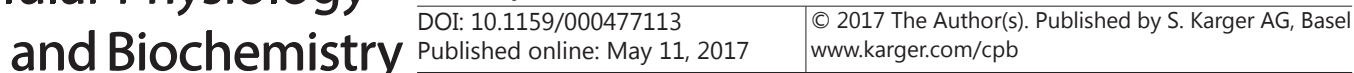

Wang et al.: Cadmium Impairs Mouse Sperm Functions

13 Yari A, Sarveazad A, Asadi E, Raouf Sarshoori J, Babahajian A, Amini N, Amidi F, Bahadoran H, Joghataei M, Asadi M, Shams A: Efficacy of Crocus sativus L. on reduction of cadmium-induced toxicity on spermatogenesis in adult rats. Andrologia 2016;10.1111/and.12568

14 Liu Q Gu JH, Yuan Y, Liu XZ, Wang YJ, Wang HD, Liu ZP, Wang ZY, Bian JC: Effect of cadmium on rat Leydig cell testosterone production and DNA integrity in vitro. Biomed Environ Sci 2013;26:769-773.

15 Hu KH, Li WX, Sun MY, Zhang SB, Fan CX, Wu Q Zhu W, Xu X: Cadmium Induced Apoptosis in MG63 Cells by Increasing ROS, Activation of p38 MAPK and Inhibition of ERK 1/2 Pathways. Cell Physiol Biochem 2015;36:642-654.

-16 Ren D, Navarro B, Perez G, Jackson AC, Hsu S, Shi Q Tilly JL, Clapham DE: A sperm ion channel required for sperm motility and male fertility. Nature 2001;413:603-609.

17 Lishko PV, Kirichok Y, Ren D, Navarro B, Chung JJ, Clapham DE: The control of male fertility by spermatozoan ion channels. Annu Rev Physiol 2012;74:453-475.

18 Darszon A, Trevino CL, Wood C, Galindo B, Rodriguez-Miranda E, Acevedo JJ, Hernandez-Gonzalez EO, Beltran C, Martinez-Lopez P, Nishigaki T: Ion channels in sperm motility and capacitation. Soc Reprod Fertil Suppl 2007;65:229-244.

19 Singh AP, Rajender S: CatSper channel, sperm function and male fertility. Reprod Biomed Online 2015;30:28-38.

20 Gallo A, Tosti E: Ion currents involved in gamete physiology. Int J Dev Biol 2015;59:261-270.

-21 Kirichok Y, Navarro B, Clapham DE: Whole-cell patch-clamp measurements of spermatozoa reveal an alkaline-activated Ca2+ channel. Nature 2006;439:737-740.

22 Qi H, Moran MM, Navarro B, Chong JA, Krapivinsky G, Krapivinsky L, Kirichok Y, Ramsey IS, Quill TA, Clapham DE: All four CatSper ion channel proteins are required for male fertility and sperm cell hyperactivated motility. Proc Natl Acad Sci U S A 2007;104:1219-1223.

-23 Navarro B, Kirichok Y, Clapham DE: KSper, a pH-sensitive K+ current that controls sperm membrane potential. Proc Natl Acad Sci U S A 2007;104:7688-7692.

24 Zeng XH, Yang C, Kim ST, Lingle CJ, Xia XM: Deletion of the Slo3 gene abolishes alkalization-activated K+ current in mouse spermatozoa. Proc Natl Acad Sci U S A 2011;108:5879-5884.

-25 Stival C, Puga Molina Ldel C, Paudel B, Buffone MG, Visconti PE, Krapf D: Sperm Capacitation and Acrosome Reaction in Mammalian Sperm. Adv Anat Embryol Cell Biol 2016;220:93-106.

-26 Carlson AE, Westenbroek RE, Quill T, Ren D, Clapham DE, Hille B, Garbers DL, Babcock DF: CatSper1 required for evoked Ca2+ entry and control of flagellar function in sperm. Proc Natl Acad Sci U S A 2003;100:14864-14868.

27 Jin J, Jin N, Zheng H, Ro S, Tafolla D, Sanders KM, Yan W: Catsper3 and Catsper4 are essential for sperm hyperactivated motility and male fertility in the mouse. Biol Reprod 2007;77:37-44.

28 Seifert R, Flick M, Bonigk W, Alvarez L, Trotschel C, Poetsch A, Muller A, Goodwin N, Pelzer P, Kashikar ND, Kremmer E, Jikeli J, Timmermann B, Kuhl H, Fridman D, Windler F, Kaupp UB, Strunker T: The CatSper channel controls chemosensation in sea urchin sperm. Embo j 2015;34:379-392.

-29 Alvarez L, Dai L, Friedrich BM, Kashikar ND, Gregor I, Pascal R, Kaupp UB: The rate of change in Ca(2+) concentration controls sperm chemotaxis. J Cell Biol 2012;196:653-663.

-30 Santi CM, Martinez-Lopez P, de la Vega-Beltran JL, Butler A, Alisio A, Darszon A, Salkoff L: The SLO3 spermspecific potassium channel plays a vital role in male fertility. FEBS Lett 2010;584:1041-1046.

-31 Wang HF, Liu M, Li N, Luo T, Zheng LP, Zeng XH: Bisphenol A Impairs Mature Sperm Functions by a CatSperRelevant Mechanism. Toxicol Sci 2016;152:145-154.

-32 Luo T, Zou QX, He YQ, Wang HF, Wang T, Liu M, Chen Y, Wang B: Matrine compromises mouse sperm functions by a [Ca(2+)]i-related mechanism. Reprod Toxicol 2016;60:69-75.

-33 Mansell SA, Publicover SJ, Barratt CL, Wilson SM: Patch clamp studies of human sperm under physiological ionic conditions reveal three functionally and pharmacologically distinct cation channels. Mol Hum Reprod 2014;20:392-408.

-34 Li HG, Ding XF, Liao AH, Kong XB, Xiong CL: Expression of CatSper family transcripts in the mouse testis during post-natal development and human ejaculated spermatozoa: relationship to sperm motility. Mol Hum Reprod 2007;13:299-306.

-35 Abarikwu SO, Olufemi PD, Lawrence CJ, Wekere FC, Ochulor AC, Barikuma AM: Rutin, an antioxidant flavonoid, induces glutathione and glutathione peroxidase activities to protect against ethanol effects in cadmium-induced oxidative stress in the testis of adult rats. Andrologia 2016;10.1111/and.12696 


\section{Cellular Physiology Cell Physiol Biochem 2017;42:44-54

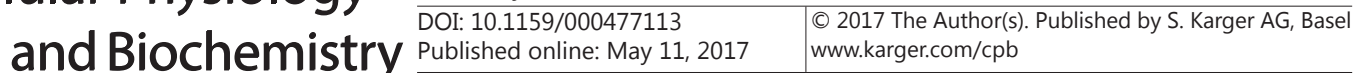

Wang et al.: Cadmium Impairs Mouse Sperm Functions

-36 Skipper A, Sims JN, Yedjou CG, Tchounwou PB: Cadmium Chloride Induces DNA Damage and Apoptosis of Human Liver Carcinoma Cells via Oxidative Stress. Int J Environ Res Public Health 2016;13:

-37 Benoff S, Auborn K, Marmar JL, Hurley IR: Link between low-dose environmentally relevant cadmium exposures and asthenozoospermia in a rat model. Fertil Steril 2008;89:e73-79.

-38 Benoff S, Hauser R, Marmar JL, Hurley IR, Napolitano B, Centola GM: Cadmium concentrations in blood and seminal plasma: correlations with sperm number and motility in three male populations (infertility patients, artificial insemination donors, and unselected volunteers). Mol Med 2009;15:248-262.

39 Miao YL, Stein P, Jefferson WN, Padilla-Banks E, Williams CJ: Calcium influx-mediated signaling is required for complete mouse egg activation. Proc Natl Acad Sci U S A 2012;109:4169-4174.

-40 Xia J, Reigada D, Mitchell CH, Ren D: CATSPER channel-mediated Ca2+ entry into mouse sperm triggers a tail-to-head propagation. Biol Reprod 2007;77:551-559.

-41 Espinosa F, Darszon A: Mouse sperm membrane potential: changes induced by Ca2+. FEBS Lett 1995;372:119-125.

42 Rossato M, Di Virgilio F, Rizzuto R, Galeazzi C, Foresta C: Intracellular calcium store depletion and acrosome reaction in human spermatozoa: role of calcium and plasma membrane potential. Mol Hum Reprod 2001;7:119-128.

43 Salvolini E, Buldreghini E, Lucarini G, Vignini A, Lenzi A, Di Primio R, Balercia G: Involvement of sperm plasma membrane and cytoskeletal proteins in human male infertility. Fertil Steril 2013;99:697-704.

44 Garza-Lopez E, Chavez JC, Santana-Calvo C, Lopez-Gonzalez I, Nishigaki T: Cd(2+) sensitivity and permeability of a low voltage-activated $\mathrm{Ca}(2+)$ channel with CatSper-like selectivity filter. Cell Calcium 2016;60:41-50.

-45 Da Costa R, Botana D, Pinero S, Proverbio F, Marin R: Cadmium inhibits motility, activities of plasma membrane $\mathrm{Ca}(2+)$-ATPase and axonemal dynein-ATPase of human spermatozoa. Andrologia 2016;48:464469.

46 Zhou X, Hao W, Shi H, Hou Y, Xu Q: Calcium homeostasis disruption - a bridge connecting cadmium-induced apoptosis, autophagy and tumorigenesis. Oncol Res Treat 2015;38:311-315.

-47 Ernesto JI, Weigel Munoz M, Battistone MA, Vasen G, Martinez-Lopez P, Orta G, Figueiras-Fierro D, De la Vega-Beltran JL, Moreno IA, Guidobaldi HA, Giojalas L, Darszon A, Cohen DJ, Cuasnicu PS: CRISP1 as a novel CatSper regulator that modulates sperm motility and orientation during fertilization. J Cell Biol 2015;210:1213-1224

48 Chung JJ, Navarro B, Krapivinsky G, Krapivinsky L, Clapham DE: A novel gene required for male fertility and functional CATSPER channel formation in spermatozoa. Nat Commun 2011;2:153.

49 Hildebrand MS, Avenarius MR, Fellous M, Zhang Y, Meyer NC, Auer J, Serres C, Kahrizi K, Najmabadi H, Beckmann JS, Smith RJ: Genetic male infertility and mutation of CATSPER ion channels. Eur J Hum Genet 2010;18:1178-1184.

50 Costello S, Michelangeli F, Nash K, Lefievre L, Morris J, Machado-Oliveira G, Barratt C, Kirkman-Brown J, Publicover S: Ca2+-stores in sperm: their identities and functions. Reproduction 2009;138:425-437.

51 Strunker T, Goodwin N, Brenker C, Kashikar ND, Weyand I, Seifert R, Kaupp UB: The CatSper channel mediates progesterone-induced Ca2+ influx in human sperm. Nature 2011;471:382-386.

52 Lishko PV, Botchkina IL, Kirichok Y: Progesterone activates the principal Ca2+ channel of human sperm. Nature 2011;471:387-391.

53 Luconi M, Krausz C, Barni T, Vannelli GB, Forti G, Baldi E: Progesterone stimulates p42 extracellular signalregulated kinase (p42erk) in human spermatozoa. Mol Hum Reprod 1998;4:251-258.

54 Rubin BS: Bisphenol A: an endocrine disruptor with widespread exposure and multiple effects. J Steroid Biochem Mol Biol 2011;127:27-34.

55 Serrano CJ, Trevino CL, Felix R, Darszon A: Voltage-dependent Ca(2+) channel subunit expression and immunolocalization in mouse spermatogenic cells and sperm. FEBS Lett 1999;462:171-176.

56 Hagar H, Al Malki W: Betaine supplementation protects against renal injury induced by cadmium intoxication in rats: role of oxidative stress and caspase-3. Environ Toxicol Pharmacol 2014;37:803-811.

57 Stajn A, Zikic RV, Ognjanovic B, Saicic ZS, Pavlovic SZ, Kostic MM, Petrovic VM: Effect of cadmium and selenium on the antioxidant defense system in rat kidneys. Comp Biochem Physiol C Pharmacol Toxicol Endocrinol 1997;117:167-172.

-58 Lopez-Gonzalez I, Torres-Rodriguez P, Sanchez-Carranza O, Solis-Lopez A, Santi CM, Darszon A, Trevino CL: Membrane hyperpolarization during human sperm capacitation. Mol Hum Reprod 2014;20:619-629. 